\title{
A Review on Synthesis and Biological Activity of Thiazole and its Derivatives
}

\author{
Namitha $\mathrm{TH}^{* 1}$, Saranya S Nair ${ }^{2}$, Dr. Arun Kumar ${ }^{3}$, Dr. Vinod B ${ }^{4}$, Dr. Daisy P A \\ ${ }^{1}$ Student, Department of Pharmaceutical Chemistry, St. joseph's College of Pharmacy, Dharmagiri Campus, Cherthala, Kerala, India. \\ ${ }^{2}$ Student, Department of Pharmaceutical Chemistry, St. Joseph's College of Pharmacy, Dharmagiri Campus, Cherthala, Kerala, India. \\ ${ }^{3}$ Assistant Professor, Department of Pharmaceutical Chemistry, St. Joseph's College of Pharmacy, Dharmagiri Campus, Cherthala, Kerala, India. \\ ${ }^{4} \mathrm{HOD}$ and Professor, Department of Pharmaceutical Chemistry, St. Joseph's College of Pharmacy, Dharmagiri Campus, Cherthala, Kerala, India. \\ ${ }^{5}$ Principal, HOD and Professor, Department of Pharmaceutics, St. Joseph's College of Pharmacy, Dharmagiri Campus, Cherthala, Kerala, India. \\ *Corresponding author's E-mail: namithahari82@gmail.com
}

Received: 17-06-2021; Revised: 21-08-2021; Accepted: 26-08-2021; Published on: 15-09-2021.

\section{ABSTRACT}

Thiazole, a five-membered heteroaromatic ring, is an important framework of a large number of synthetic compounds. Its diverse pharmacological activity is mirrored in many clinically approved thiazole-containing molecules with, wide range of biological activities, such as antibacterial, antifungal, antiviral, anthelmintic, antitumor, and anti-inflammatory effects. The current review provides an overview of the biological activities of thiazole during the past years.

Keywords: Thiazole; synthesis; derivatives; biological activities.

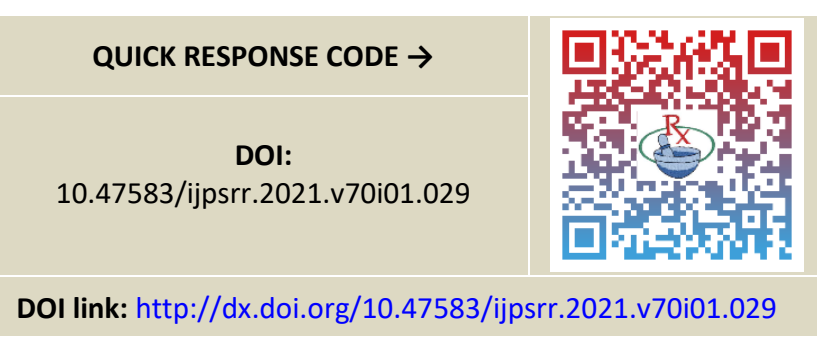

\section{INTRODUCTION}

$\mathrm{N}$ itrogen-containing heterocyclic compounds play an important role in the drug discovery process, as nearly $75 \%$ of FDA (Food and Drug Administration)-approved small-molecule drugs contain one or more nitrogen-based heterocycles. Thiazole, or 1,3thiazole, fits to the class of azoles and contains one sulfur atom and one nitrogen atom at positions 1 and 3. The thiazole nucleus is a very imperative heterocycle in many biologically active compounds that makes it one of the broadly studied heterocycles ${ }^{1-3}$. Thiazole plays vital roles in many drug structures. Tiazofurin and dasatinib (antineoplastic agents), ritonavir (anti-HIV drug), ravuconazole (antifungal agent) nitazoxanide (antiparasitic agent), fanetizole, meloxicam and fentiazac (antiinflammatory agents), nizatidine (antiulcer agent), and thiamethoxam (insecticide) are some examples for thiazole bearing products.

The current reports have been stated the applications of thiazole core structure in drug design and development of novel therapeutic agents. Thiazole ring as part of fivemembered heterocycles has been used various roles in the lead identification and optimization, including as pharmacophoric and bio isosteric elements, and as a spacer. Also, the presence of thiazole ring as a part of drug structure can be determinant for its physicochemical and pharmacokinetic properties.

This review is intended to define the structural and biological importance of thiazole in drug design and discovery by emphasis on recent publications about diverse compounds containing thiazole ring and their different biological activities.

\section{Structural Characteristics}

Thiazole, or 1,3-thiazole is a clear to pale yellow flammable liquid with a pyridine-like odour and the molecular formula C3H3NS. It is a 5-membered ring, in which two of the vertices of the ring are nitrogen and sulfur, and other three are carbons. The numbering system is shown below for naming derivatives of thiazole (Figure:1).

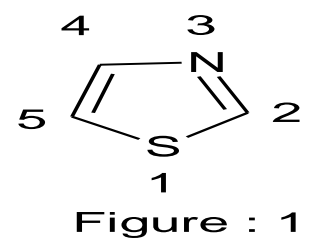

Thiazoles are a class of organic compounds related to azoles with a common thiazole moiety is a crucial part of vitamin B1 and epothilone. It is an aromatic compound, satisfies Huckel's rule. Delocalization of a lone pair of electrons from the sulfur atom complete the $6 \pi$ electrons. The resonance forms are (Figure : 2 ): ${ }^{4}$

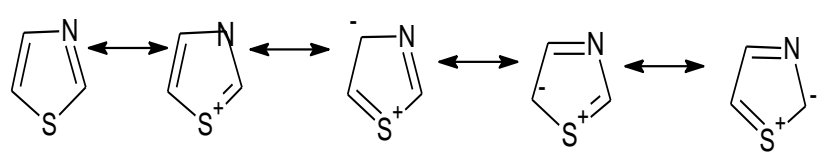

Figure : 2 


\section{Properties}

Physical Properties

- Thiazole generally pale-yellow flammable liquid.

- It has pyridine like odour.

- It is fairly soluble in ether and alcohol but sparingly soluble in water.

- It has a boiling point of $116-118^{\circ} \mathrm{c}$ and pka of 2.5 (conjugated acid).

- Its density is $1.2 \mathrm{gm} / \mathrm{cm} 3$ and its ionization potential is $9.50 \mathrm{Ev}$.

- It has a dipole moment of 1.61D.

\section{Chemical Properties}

\section{Nucleophilic Substitution Reaction}

As evident from the electron density map, $C_{2}$, the electronically poor carbon center, is the preferred site for nucleophilic substitution. Diazonium salt derived from 2aminothiazole undergoes nucleophilic substitution with sodium bromide in the presence of copper sulfate to give 2-bromothiazole ${ }^{5}$ (Figure : 3 ).

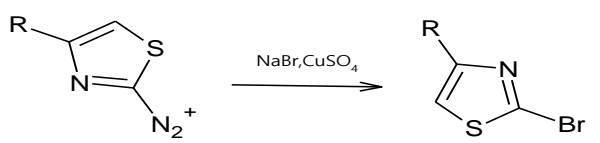

Figure : 3

Reagents with high nucleophilicity such as sodamide on reaction with 3-methylthiazole afforded 2-amino-3methylthiazole ( Figure : 4).

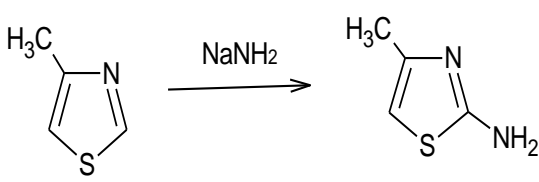

Figure : 4

\section{Dimerization Reactions}

Palladium acetate-catalyzed dimerization of 2bromothiazole in the presence of a phase transfer catalyst $\left(\mathrm{Bu}{ }_{4} \mathrm{NBr}\right)$ and diisopropylethylamine (DIPEA) in toluene at $105^{\circ} \mathrm{C}$ for $23 \mathrm{~h}$ gave 2,2'-bisthiazole in $86 \%$ yields ${ }^{5}$ (Figure: 5 ).<smiles>Brc1nccs1</smiles>

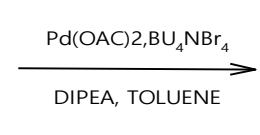<smiles>c1csc(-c2nccs2)n1</smiles>

Figure : 5

\section{Cycloaddition Reactions}

2-Isopropylthiazole on reaction with dichloroketene underwent $[2+2+2]$ cycloaddition to give a bicyclic product $^{5}$ (Figure : 6).

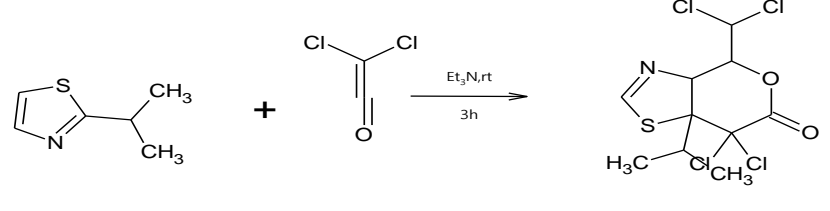

Figure : 6

\section{Metal-Mediated Coupling Reactions}

Coupling of 2-iodothiazole with 1 -((phenylsulfonyl)- $1 H$ indol 3yl)zinc iodide afforded 2-(1- (phenylsulfonyl)- $1 \mathrm{H}-\mathrm{I}$ indol-3-yl)thiazole ${ }^{5}$ ( Figure : 7).

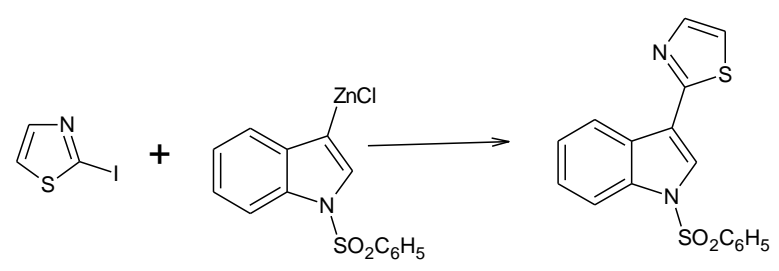

Figure:7

\section{Oxidation}

Thiadiazoles are resistant to oxidizing agents but they do oxidize with hydrogen peroxide or peracids such as perbenzoic or peracetic acid to thiazole- $N$-oxide (Figure : 8).<smiles>Cc1csc(C)n1</smiles>

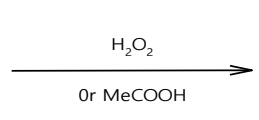<smiles>Cc1csc(C)[n+]1O</smiles>

Figure : 8

\section{Reduction}

Reduction of thiazoles is a very useful method for the preparation of aldehydes in three steps. The first step is the preparation of $\mathrm{N}$-methyl thiazolium salt and the second step is the reduction of thiazolium cation with $\mathrm{NaBH} 4$. Finally, $\mathrm{HgCl} 2$-promoted hydrolysis of reduced thiazole intermediate afforded aldehyde ( Figure : 9).

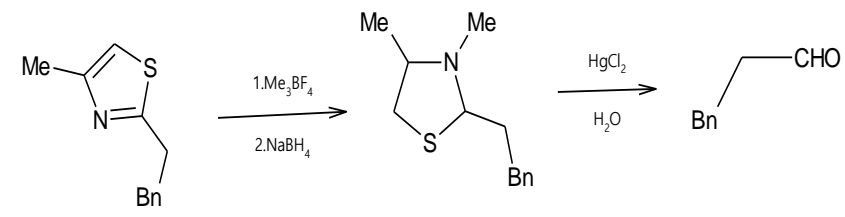

Figure : 9

Synthesis of Thiazole and Its Derivatives

\section{Gabriel Synthesis}

Parent and 2,5-disubstituted thiazoles have been prepared from the reaction of $\alpha$-acylamino ketones or amino acetal on reaction with phosphorous pentasulfide in good yields 5 (Figure : 10 ).<smiles>[R]C(NC=O)C(=O)CC</smiles><smiles>[R]c1ncsc1CC</smiles>

Figure : 10 


\section{Cook-Heilborn's Synthesis}

Cook-Heilborn's synthesis is a versatile protocol for the construction of 5-amino thiazole from the reaction of $\alpha$ aminonitriles with dithioacid or esters, $\mathrm{CS}_{2}$, carbonyl sulfide, and isothiocyanates separately ${ }^{6}$ (Figure : 11)

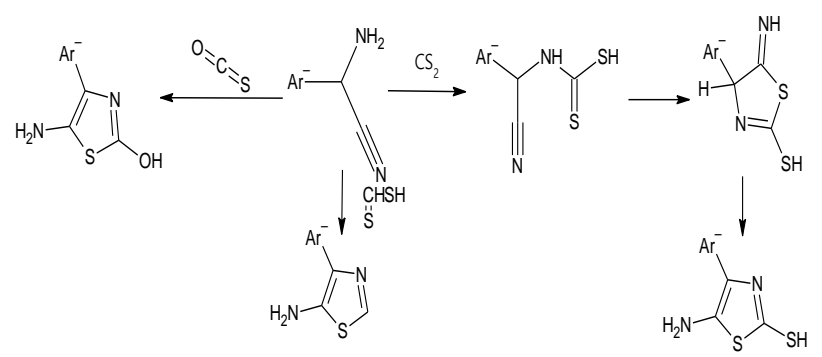

Figure : 11

Condensation of equimolar thiourea and $\alpha$-haloketones or aldehyde afforded 2-aminothiazole (Figure : 12).<smiles>O=CCCl</smiles><smiles>NC(N)Sc1ncsc1P</smiles>

Figure : 12

Treatment of $N, N$-diformylaminomethyl aryl ketones with $\mathrm{P}_{2} \mathrm{~S}_{5}$ and triethylamine in chloroform afforded 5arylthiazoles in good yields (Figure : 13).<smiles>O=CN(C=O)CC(=O)[18O][Mg]</smiles>

Figure : 13

Cuprous iodide- catalyzed three component condensation of aldoximes, anhydride, and potassium thiocyanate (KSCN) in toluene at $120^{\circ} \mathrm{C}$ provided 2,5-disubstituted thiazoles in good yields under mild reaction conditions ( Figure : 14).

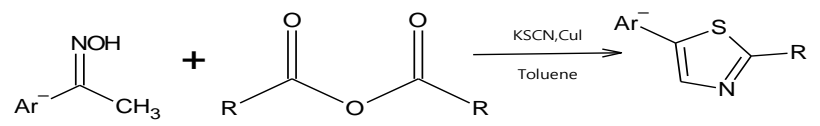

Figure : 14

5-Aryl-2-aminothiazoles have been synthesized by $\mathrm{Pd}(\mathrm{II})$ acetate-catalyzed reaction of vinyl azides and potassium thiocyanates using Fe(III) bromide as promoter (Figure : 15)

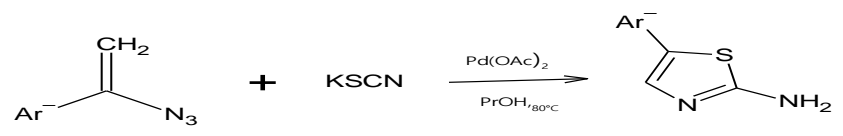

Figure : 15

\section{Pharmacological Activities}

\section{Antifungal and Antibacterial Agents}

The resistance of fungi and bacteria towards the antimicrobial drugs is increasing rapidly due to the nonselective antimicrobial activities and a limited number of drugs. To overcome this situation, many thiazole containing molecules are synthesized to cure bacterial and fungal infections.

Bera et al. synthesized pyridinyl thiazole ligand having hydrazone moiety by condensing 2-bromo-4- methoxy acetophenone with 2-acetylpyridine thiosemicarbazone. They also prepared cobalt complex by treating this ligand with cobalt precursor. Both the ligand and its complex were tested for anti-bacterial properties towards gram positive bacteria including Bacillus subtilis, Streptococcus fecalis, Staphylococcus aureus and gram-negative bacteria including Pseudomonas aeruginosa, Salmonella typhi, Escherichia coli, Klebsiella pneumonia and Proteus vulgaris ${ }^{8}$.

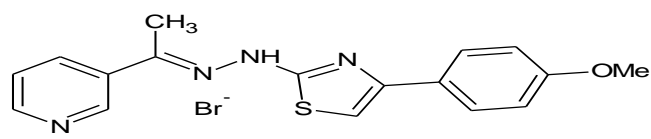

Figure 16: Pyridinyl thiazole ligand with antimicrobial activity

\section{Anticancer Agents}

Mohammadi-Farani et al. reported a new series of thiazole derivatives (Fig. 17) and they studied the anti-tumor activity of these molecules against Hep-G2 (Human hepatocarcinoma) MCF-7 (Breast cancer) and human cancerous cell lines SKNMC (Neuroblastoma). Based on the results compounds with nitro groups at para position and chloro group at meta position displayed maximum anticancer activity against SKNMC cells and Hep-G2 with IC50 values 10.8 and $11.6 \mu \mathrm{M}$ respectively ${ }^{9}$.

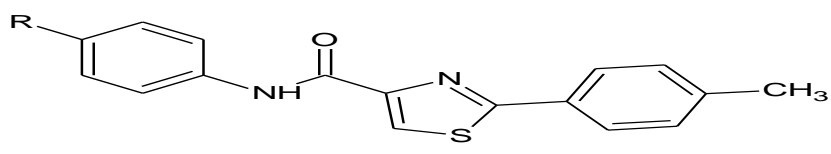

$\mathrm{R}=\mathrm{o}-\mathrm{NO} 2, \mathrm{~m}-\mathrm{NO} 2, \mathrm{p}-\mathrm{NO} 2, \mathrm{~m}-\mathrm{Cl}, \mathrm{p}-\mathrm{Cl}, \mathrm{p}-\mathrm{F}$

Figure 17: 2-Phenylthiazole-4-carboxamides having anticancer activities.

\section{Antiviral Agents}

Curreli et al. studied the synthesis of thiazole derivatives carrying oxalamides unit (Fig. 18) and these molecules screened against HIV virus. According to the results both the molecules showed better activity against HIV-1. The molecules target the HIV virus and disrupt the CD-4 binding site. Thus, the molecules avoid the entry of the virus into the host cell ${ }^{10}$.

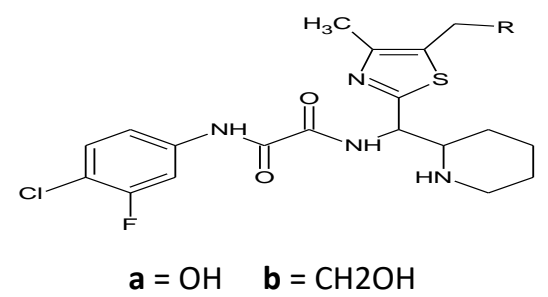

Figure 18: Thiazole carrying oxalamides moiety. 


\section{Anti-TB Agent}

Lu et al., prepared ester substituted thiazole derivatives (Fig. 19) and tested for anti-tubercular activity against M. tuberculosis H37Rv and $\mathrm{S}$. pneumonia with minimum inhibition concentration value in the range of 1.0-61.2 $\mu \mathrm{M}$ and $0.117-0.131 \mu \mathrm{M}$ respectively. Among the synthesized molecules, the compound having ethyl ester and $4-\mathrm{Cl}$ phenyl group attached to amide groups was found to be most activewith MIC value $1.0 \mathrm{Mm}^{11}$.

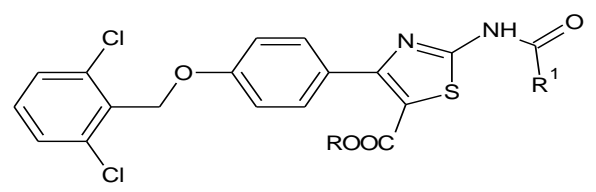

$\mathrm{R}=\mathrm{Et}, \mathrm{H}$

$\mathrm{R} 1=\mathrm{Ph}, 4-\mathrm{Cl}-\mathrm{Ph}, 2,4 \mathrm{Cl}-\mathrm{Ph}, 4-\mathrm{CH} 3 \mathrm{O}-\mathrm{Ph}, \mathrm{n}-\mathrm{Pr}$, Ethylene

Figure 19: Thiazole derivatives having anti-TB activity.

\section{Antioxidant Agents}

Ahmed et al. studied the antioxidant activity of thiazole derivatives (Fig. 20). The compound showed potent activity against erythrocyte haemolysis (0.85\%) compared to that of standard ascorbic acid ${ }^{12}$.

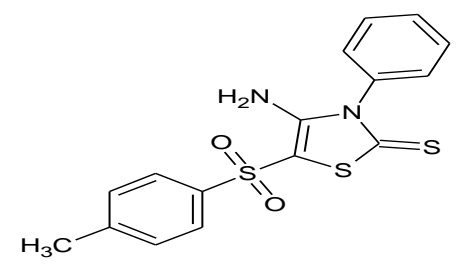

Figure 20: Thiazole derivative as potent antioxidant agent.

Grozav et al reported the synthesis and antioxidant activity of thiazole derivatives carrying indole moiety (Fig. 21). These compounds showed better activity compared to standard drug Trolox which shows the IC50 value of 9.74 $\mu \mathrm{g} / \mathrm{mL}$.. Antioxidant studies were carried out using the spectrophotometric method. The reducing ability of thiazole derivatives was measured as ferric reducing antioxidant power (FRAP). Reduction of ferric ion (Fe3+) to ferrous ion $(\mathrm{Fe} 2+)$ from tripyridyltriazine $\mathrm{Fe}$ (TPTZ)3+ depends on electron donating ability of thiazole derivatives ${ }^{13}$.<smiles>[R]c1nc(N/N=C/c2ccc3[nH]ccc3c2)sc1[R7]</smiles>

$\mathrm{a}=\mathrm{R} 1=\mathrm{Me}, \mathrm{R} 2=\mathrm{H}$

$\mathrm{b}=\mathrm{R} 1=\mathrm{Me}, \mathrm{R} 2=\mathrm{COMe}$

$\mathrm{C}=\mathrm{R} 1=\mathrm{Ph}, \mathrm{R} 2=\mathrm{H}$

$\mathrm{d}=\mathrm{R} 1=\mathrm{Me}, \mathrm{R} 2=\mathrm{COOEt}$

$\mathrm{e}=\mathrm{R} 1=\mathrm{CH} 2 \mathrm{COOEt}, \mathrm{R} 2=\mathrm{H}$

$f=R 1=$ COOEt, $R 2=H$

Figure 21: Thiazole derivatives as antioxidant agent.

\section{Marketed Formulations}

The list of thiazole containing clinically used drugs or drug candidates includes Pramipexole, Acinitrazole, Sulfathiazole, Bleomycin, Tiazofurin, Ritonavir, Cinalukast, Nizatidine, Fenetizole, and Meloxicam.

\section{Pramipexole}<smiles>CCCN[C@H]1CCc2nc(N)sc2C1</smiles>

Figure : 22

- Pramipexole is a tetrahydro benzothiazole derivatives, formulated as di-HCL salt ( side chain $\mathrm{NH}$ and hetero $\mathrm{N}$ ) of pharmacologically active single ( S-(-)) isomer.

- Pramipexole is rapidly absorbed after oral administration.

\section{Mechanism of Action}

This is a nonergot dopamine agonist that is approved for the treatment of Parkinson's disease. Pramipexole alleviates the motor deficts in patients who have never taken levodopa and also in patients with advanced Parkinson's disease. In normal dopaminergic systems, pramipexole act on presynaptic D2 and D3 dopamine auto receptors and suppresses the synthesis and synaptic release of dopamine ${ }^{14}$.

\section{Sulfathiazole}

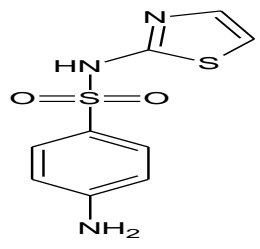

Figure : 23

- Sulfathiazole is a short-acting sulfa drug.

- It used to be a common oral and topical antimicrobial.

- It is effective against a wide range of gram positive and gram negative. pathogenic microorganisms.

- Although no longer used in humans, it is used in cattle.

\section{Mechanism of Action}

Sulfathiazole interferes with synthesis of folic acid that bacteria require for growth hence it prevent the further bacterial growth ${ }^{15}$.

\section{CONCLUSION}

Thiazole nucleus has occupied a pivotal position in the modern organic and medicinal chemistry due to its broadspectrum pharmacological activities such as antimicrobial, anticancer, antioxidant and antiviral. The presence of thiazole ring in many drugs such febuxostat, dasatinib and ravuconazole motivate the chemists to design new thiazole scaffolds. Thiazole nucleus exhibited an important role in finding new leads and drugs for various diseases. In 
this review we have focused our attention on recent synthetic and biological application of thiazole derivatives. This review helps to design new thiazole-based molecules for different biological targets.

\section{REFERENCES}

1. Nayak S, Gaonkar SL. A review on recent synthetic strategies and pharmacological importance of 1, 3-thiazole derivatives. Mini reviews in medicinal chemistry. 2019 Feb 1; 19(3): 21538.

2. Borcea AM, lonuț I, Crișan O, Oniga O. An overview of the synthesis and antimicrobial, antiprotozoal, and antitumor activity of thiazole and bisthiazole derivatives. Molecules. Jan; 26(3): 624.

3. Siddiqui N, Arshad MF, Ahsan W, Alam MS. Thiazoles: a valuable insight into the recent advances and biological activities. Int J Pharm Sci Drug Res. 2009; 1(3): 136-43.

4. Abdu-Rahem LR, Ahmad AK, Abachi FT. Synthesis and Medicinal Attributes of Thiazole Derivatives: A Review. Systematic Reviews in Pharmacy.; 12(1): 290-5.

5. Ram VJ, Sethi A, Nath M, Pratap R. The Chemistry of Heterocycles: Nomenclature and Chemistry of Three to Five Membered Heterocycles. Elsevier; 2019 May 15.

6. Li JJ. Cook-Heilbron thiazole synthesis. InName Reactions 2003 (pp. 82-82). Springer, Berlin, Heidelberg.

7. Grange JM, Zumla A. The global emergency of tuberculosis: what is the cause? The journal of the Royal Society for the Promotion of Health. 2002 Jun; 122(2): 78-81.

8. Pradip Bera, Paula Brandão, Gopinath Mondal, Harekrishna Jana, Abhimanyu Jana, Ananyakumari Santra, Pulakesh Bera , Synthesis of a new pyridinyl thiazole ligand with hydrazone moiety and its cobalt(III) complex: X-ray crystallography, in vitro evaluation of antibacterial activity, 2017; 134: 230-237.

9. Mohammadi-Farani A, Foroumadi A, Kashani MR, Aliabadi A. $\mathrm{N}$-Phenyl-2-p-tolylthiazole-4-carboxamide derivatives: Synthesis and cytotoxicity evaluation as anticancer agents. Iranian Journal of basic medical sciences. 2014 Jul; 17(7): 502.

10. Curreli F, Choudhury S, Pyatkin I, Zagorodnikov VP, Bulay AK, Altieri A, Kwon YD, Kwong PD, Debnath AK. Design, synthesis, and antiviral activity of entry inhibitors that target the CD4-binding site of HIV-1. Journal of medicinal chemistry. 2012 May 24; 55(10): 4764-75.

11. Lu X, Liu X, Wan B, Franzblau SG, Chen L, Zhou C, You Q. Synthesis and evaluation of anti-tubercular and antibacterial activities of new 4-(2, 6-dichlorobenzyloxy) phenyl thiazole, oxazole and imidazole derivatives. Part 2. European journal of medicinal chemistry. 2012 Mar 1; 49: 164-71.

12. Fadda AA, Berghot MA, Amer FA, Badawy DS, Bayoumy NM. Synthesis and antioxidant and antitumor activity of novel pyridine, chromene, thiophene and thiazole derivatives. Archiv Der Pharmazie. 2012 May; 345(5): 378-85.

13. Grozav A, Porumb ID, Găină LI, Filip L, Hanganu D. Cytotoxicity and Antioxidant Potential of Novel 2-(2- $((1 \mathrm{H}-$ indol-5yl) methylene)-hydrazinyl)-thiazole Derivatives. Molecules. 2017 Feb; 22(2): 260.

14. Holloway RG, Bigl KM. A review of pramipexole and its clinical utility in Parkinson's disease. Expert opinion on pharmacotherapy. 2002 Feb 1; 3(2): 197-210.

15. Eric M., University of Nebraska Medical Center, Omaha, United States, xPharm: The Comprehensive Pharmacology Reference, 2009; page 1-3.

Source of Support: The author(s) received no financial support for the research, authorship, and/or publication of this article.

Conflict of Interest: The author(s) declared no potential conflicts of interest with respect to the research, authorship, and/or publication of this article.

For any question relates to this article, please reach us at: editor@globalresearchonline.net New manuscripts for publication can be submitted at: submit@globalresearchonline.net and submit_ijpsrr@rediffmail.com 